\title{
Perceptual filling-in of stereoscopically presented targets
}

\author{
Preenchimentoperceptualde estímulos estereoscópicos
}

\author{
Márcia Furukawa Couto ${ }^{1}$ \\ Valdir Filgueiras Pessoa ${ }^{2}$
}

\begin{tabular}{l} 
ABSTRACT \\
\hline Purpose: To investigate the influence of parametric variation on the filling- \\
in latency of stereoscopically presented stimuli. Methods: Anaglyphs \\
were created using two circular patches of $0.3^{\circ}$ diameter, $0.5^{\circ}$ disparity and \\
$6^{\circ}$ eccentricity from fixation point. Targets were presented at the visual field \\
midline, $90^{\circ}$ and $270^{\circ}$ positions, with crossed and uncrossed disparity. The \\
time elapsed for disappearance of the target under voluntary steady \\
fixation was computed. Eighteen subjects tested. Results: There was no \\
significant difference between crossed and uncrossed disparities, nor \\
between near or far from the vertical horopter line. The significant difference \\
was between upper and lower visual field positions. Conclusion: The \\
results show that: (i) stereoscopic presentation does not influence the \\
target filling-in latency; (ii) differences between dorsal and ventral visual \\
stream might influence target filling-in latency.
\end{tabular}

Keywords: Perceptual masking; Vision disparity/physiology; Visual perception/physiology; Visual field

\section{INTRODUCTION}

Perceptual filling-in is a strategy used by the brain to deal with undersampled or blind regions of the visual field, the scotomas. Natural scotomas are generated by anatomical structures like the optic nerve head and retinal blood vessels; acquired scotomas can appear after retinal and/or central neural lesions. Usually these blind areas are not perceived by individuals because their visual system fills in according to the visual pattern from their surrounding areas $^{(1-2)}$.

It is possible to create an 'artificial scotoma' by insertion of a small peripheral target on a display with a twinkling pattern of dots. Ramachandran and Gregory ${ }^{(3)}$ reported that after a few seconds of central steady fixation, the target disappears. This effect is similar to Troxler fading, the tendency for small stationary objects in the peripheral visual field to disappear completely on steady prolonged fixation.

The literature has examined the effect of many stimulus parameters on perceptual filling-in of artificial scotomas including brightness, contrast, target size, color, shape and eccentricity. De Weerd et al. ${ }^{(4)}$ found that filling-in latency depends on: (i) the total target cortical projection area, occurring faster for more peripheral and smaller ones; and on (ii) the boundary length of target cortical projection, reflecting the time required for the segregation between the target and its surround to disappear. Friedman et al. ${ }^{(5)}$ found that filling-in is faster for colored circles with blurred than with sharp edges. Welchman and Harris ${ }^{(6)}$ found longer time to fade as they increased motion speed to dots at the target surroundings. Sakaguchi ${ }^{(7)}$ studied target/surround contrast and found faster filling-in for less contrast; and when the target was brighter than the surrounding areas. 
On the other hand, Welchman and Harris ${ }^{(8)}$ investigated the influence of degrading the target's border on filling-in and found no difference of target filling-in latencies (TFLs) between the levels of blur. They also managed to blur the borders of depth targets creating a cloud of different depths, and found no significant effect of this change on TFLs. These results suggest that filling-in phenomenon might be not influenced by some visual parameters.

We will be investigating whether filling-in latency is differentially affected by presenting stereoscopic targets. Stimuli with crossed disparity gives to the viewer the feeling of closer targets as opposed to uncrossed disparity which makes them seem farther. Furthermore, stereoscopic stimuli with crossed disparity are easier to detect than the ones with uncrossed disparity at all visual field positions ${ }^{(9)}$, especially in the lower field ${ }^{(10)}$. Psychophysical and electrophysiological studies provide evidence that crossed and uncrossed disparities may be processed by separate neural pools or classes of cells that have: (i) different sensitivities; (ii) different spatial properties; and (iii) perhaps different temporal constants ${ }^{(11)}$. Considering the differences listed above, and that targets situated closer to the observer might take longer latencies to fade than farther ones, we expect longer TFLs for stereoscopic targets with crossed disparity than with uncrossed disparity.

The vertical horopter is another aspect of stereoscopic processing which might influence the TFLs. A horopter is the sum of all points in space whose images form at corresponding points on the plane of the retina and perceived to have zero disparity. The vertical horopter is defined by a vertical line in the space which has the lowest stereo-threshold. It is generally recognized as having a backwards tilt passing through the fixation point and a point near the feet of the observer. The backwards tilt is attributed to a shear in retinal correspondence in the vertical meridian and/or torsional eye movements ${ }^{(12)}$. The tilt decreases from an average of $12^{\circ}$ at $2 \mathrm{~m}$ to $3^{\circ}$ at $50 \mathrm{~cm}$, with some variability amongst observers ${ }^{(12)}$ and has been used by computer monitor screens and eye glass industries to improve users comfort ${ }^{(13)}$.

In addition, there are evidences of functional specialization of the upper and lower visual fields, yielding better peripersonal (or crossed disparity) processing at the lower field, and better extrapersonal (or uncrossed disparity) processing at upper field $^{(14)}$. At the upper visual field the stimulus with uncrossed disparity is nearer the vertical horopter than the one with crossed disparity. At the lower visual field the stimulus with crossed disparity is nearer the vertical horopter than the one with uncrossed disparity. We will compare TFLs from stimuli situated nearer and farther from the vertical horopter. We will also compare TFLs between upper and lower visual fields.

\section{METHODS}

\section{Subjects}

Eighteen trichromats were selected, seven males and eleven females including the author M.C., with stereoacuity of 50 seconds of arc or better and normal corrected near visual acuity. The age range was 18 to 50 years. All subjects gave their informed consent. The Brasília University's Human Research Ethics Committee has approved this protocol, which has adhered to the tenets of the Declaration of Helsinki. All subjects, except the author, were naive to the purpose of the experiment.

\section{Apparatus and stimuli}

Stimuli were generated by an IBM compatible personal computer, equipped with Matlab software and presented on a 17-inch color monitor (Samsung Sync Master 753 DFX). A black cross in the center of the screen was used for voluntary fixation on every trial.

Anaglyphs were created using two circular patches, one blue [Commission Internationale de l'Eclairage (CIE) $\mathrm{x}=0.238$, $\mathrm{y}=0.233$ ] and one orange [CIE $\mathrm{x}=0.359, \mathrm{y}=0.470$ ], both with $0.3^{\circ}$ diameter, $0.5^{\circ}$ of horizontal disparity.

Blue and orange $4 \times 4 \mathrm{~cm}$ filters were assembled as eye glasses. The blue filter (band-pass 420 to $475 \mathrm{~nm}$ ) was used at the right eye; the orange filter (band-pass 616 to $627 \mathrm{~nm}$ ) at the left eye, to produce stereo-stimuli. (The right eye sees only the orange patch, while the left eye sees only the blue patch).

The circular stereoscopic patches were presented at $6^{\circ}$ of eccentricity from central fixation cross, at the visual field midline, on a uniform gray background (36 candelas/meter ${ }^{2}$ of luminance). Crossed and uncrossed disparities were used for these stereoscopic targets at two angular positions: $90^{\circ}$ (upper visual field) and $270^{\circ}$ (lower visual field). A black cross in the center of the screen was used for fixation. The $6^{\circ}$ eccentricity was chosen due to diplopia elicited for more eccentric stereo-stimuli and much longer filling-in latencies for targets closer to the center. Although the eccentricity that we used is outside parafoveal area, it was close enough to guarantee good stereoacuity ${ }^{(15)}$.

Subjects performed a total of 32 trials for each target possibility.

\section{Procedure}

Subjects were kept under scotopic conditions 5 minutes prior to testing to produce uniform adaptation status at the beginning of the experiment. They were positioned at $57 \mathrm{~cm}$ from the screen with chin rest; the experiment was run in a dark room.

The subjects were asked to maintain voluntary steady fixation at the central cross and were instructed to press "enter" on the computer keyboard as soon as they realized the target had faded. They were allowed to blink normally. The time between stimulus onset and the subject's response was recorded as the target filling-in latency (TFL).

Each trial was preceded by a gray screen, without the target, lasting 2 seconds in order to eliminate afterimage of the previous stimulus. Due to the characteristics of the stimuli, all experiments were performed binocularly. Each experimental session took approximately 1 hour. 


\section{Statistical analysis}

Data are expressed as the filling-in latency mean \pm standard error of the mean and are statistically analyzed by twoway ANOVA. The significance level is set to 5\%; null hypothesis is that there is no effect of target position on the TFL results.

\section{RESULTS}

TFL results are analyzed for two main aspects: (i) visual field position; and (ii) the stereoscopic parameters (disparity type and proximity to vertical horopter line). Two way ANOVA (i vs. ii) reveals that subjects present a significant difference between upper and lower visual field's TFL ( $<<0.05$, $\left.\mathrm{F}_{3.8}=59.642\right)$. However, no significant difference between stereoscopic parameters is found ( $\left.\mathrm{p}>0.05, \mathrm{~F}_{2.6}=0.259\right)$ nor interaction between factors ( $p>0.05$ ) (Figure 1 ).

\section{DISCUSSION}

In this study we investigated the importance of target spatial presentation on the filling-in latency. Previous parametric studies using the artificial scotoma model indicate that target/surround contrast, eccentricity, size and color variations can facilitate or impair filling-in ${ }^{(3-7,16-17)}$. Targets situated closer to the fixation point, with increased size and high target/surround contrast take longer time to fade than the smaller and peripheral ones with less contrast.

Despite the differences between crossed and uncrossed disparity processing listed in the introduction, in our experiment the disparity type did not influence TFL. We also compa-

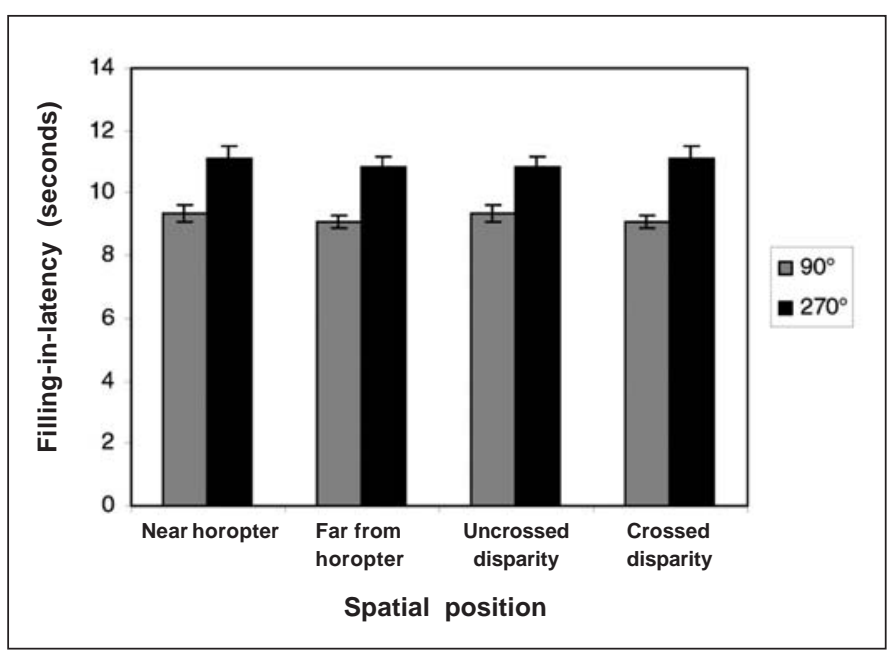

Figure 1 - Target filling-in latency data for all subjects showing the comparison between $90^{\circ}$ and $270^{\circ}$ for: (i) near and (ii) far from the vertical horopter; (iii) crossed and (iv) uncrossed disparity. There is a significant difference between $90^{\circ}$ and $270^{\circ}$ positions. There are no differences between the stereoscopic parameters. Error bars represent \pm standard error of the mean. red data pooled as nearer and farther from the vertical horopter, considering that our stimuli were placed at the vertical midline. In our experiments, the upper uncrossed and the lower crossed targets were situated nearer the vertical horopter line than the upper crossed and the lower uncrossed which were situated farther from it. However, no significant difference of TFLs between nearer and farther from vertical horopter was found.

These results indicate that the influence of parametric variation on filling-in phenomenon is limited. If an object situated at the visual periphery becomes invisible by the effect of neural filling-in, it seems to be mostly influenced by features as its brightness and the size of its cortical projection. Differences elicited by border degradation ${ }^{(8)}$ or depth variation from the fixation plane exert no significant effect on the time it takes to fill-in, at least on the extent evaluated here.

In our experiment, the significant result was the difference of TFLs between upper and lower visual field position. Couto ${ }^{(18)}$ and Sakaguchi ${ }^{(19)}$ investigated filling-in of a gray target at different polar angles (without depth variation) and also found faster filling-in at the upper visual field and slower at the lower one, but did not offer an explanation for this difference.

Differences of visual processing between upper and lower visual fields might explain our results. The superior retina has a greater ganglion cell density than the inferior retina, yielding larger representation of the lower visual field at the cortex ${ }^{(20)}$. It has been demonstrated that the lower visual field has advantage in visuomotor coordination ${ }^{(21)}$ and in spatial memory tasks as compared to the upper visual field ${ }^{(22)}$. The perception of illusory contours ${ }^{(23)}$, color motion ${ }^{(24)}$ and length judgment $^{(25)}$ is enhanced in the lower visual field. Also, the EEG occipital scalp field peak much earlier for upper than for lower hemiretinal stimulation ${ }^{(26)}$. On the other hand, the upper visual field has advantage in object search and recognition as compared to the lower visual field ${ }^{(27)}$.

Difference is also evident between dorsal and ventral visual streams that begin with $\mathrm{V} 1$. The ventral stream projects to temporal lobe (V4), while dorsal stream projects to the parietal lobe (MT). It has been proposed that the ventral visual stream plays the major role in the identification of objects, while the dorsal stream mediates the required sensorimotor transformations for visually guided actions ${ }^{(28)}$.

There is an upper visual hemifield advantage for allocentric spatial judgments required to perform a location task and a lower visual hemifield advantage when egocentric spatial judgments are required. This is interpreted as due to the activity of two separate neural pathways: scene recognition by the ventral visual pathway and goal directed actions by the dorsal visual pathway ${ }^{(29)}$.

It has been suggested that these functional differences might be related to ecological and evolutionary aspects of the visual system ${ }^{(14)}$. All these differences may contribute to enhance saliency of targets situated at the lower visual field and consequently delay its fading. 


\section{CONCLUSIONS}

1) Stereoscopic parametric variation is not crucial for the neural filling-in processing, in contrast to target size, eccentricity and brightness.

2) The advantage of upper visual field on search and identification tasks, opposed to the advantage of lower visual field on action related tasks, might influence neural filling-in process; these differences could be responsible for a delayed fading of a target or an object placed at the lower visual field, since it is identified and submitted to additional coding process preparing to action purposes such as visually guided reaching and grasping.

\section{RESUMO}

Objetivo: Investigar a influência da variação de parâmetros estereoscópicos na latência de preenchimento perceptual de estímulos 3D. Métodos: Criados anáglifos com dois discos de $0,3^{\circ}$ de diâmetro, $0,5^{\circ}$ de disparidade e $6^{\circ}$ de excentricidade do ponto central de fixação. Estímulos foram apresentados na linha central do campo visual, nas posições $90^{\circ}$ e $270^{\circ}$, com disparidade cruzada e não cruzada. Registrado o tempo gasto para o preenchimento do estímulo sob fixação estável. Testados dezoito indivíduos. Resultados: Não houve diferença significativa entre as disparidades cruzada e não cruzada, nem entre perto e longe da linha do horóptero vertical. Houve diferença significativa entre posição superior e inferior do campo visual. Conclusão: Os resultados mostram que: (i) a apresentação estereoscópica não tem influência na latência de preenchimento perceptual, (ii) diferenças entre o sistema visual dorsal e ventral podem influenciar a latência de preenchimento perceptual.

Descritores: Mascaramento perceptivo; Disparidade visual/ fisiologia; Percepção visual/fisiologia; Campo visual

\section{REFERENCES}

1. Ramachandran VS. Blind spots. Sci Am. 1992;266(5):86-91.

2. Pessoa L, Thompson E, Noe A. Finding out about filling-in: a guide to perceptual completion for visual science and the philosophy of perception. Behav Brain Sci. 1998;21(6):723-48; discussion 748-802.

3. Ramachandran VS, Gregory RL. Perceptual filling-in of artificially induced scotomas in human vision. Nature. 1991;350(6320):699-702.
4. De Weerd P, Desimone R, Ungerleider LG. Perceptual filling-in: a parametric study. Vision Res. 1998;38(18):2721-34.

5. Friedman HS, Zhou H, von der Heydt R. Color filling-in under steady fixation: behavioral demonstration in monkeys and humans. Perception. 1999; 28(11):1383-95.

6. Welchman AE, Harris JM. Filling-in the details on perceptual fading. Vision Res. 2001;41(16):2107-17.

7. Sakaguchi Y. Target/surround asymmetry in perceptual filling-in. Vision Res. 2001;41(16):2065-77.

8. Welchman AE, Harris JM. Is neural filling-in necessary to explain the perceptual completion of motion and depth information? Proc Biol Sci. 2003;270 (1510):83-90.

9. Manning ML, Finlay DC, Neill RA, Frost BG. Detection threshold differences to crossed and uncrossed disparities. Vision Res. 1987;27(9):1683-6.

10. Breitmeyer B, Julesz B, Kropfl W. Dynamic random-dot sterereograms reveal up-down anisotropy and left-right isotropy between cortical hemifields. Science. $1975 ; 187(4173): 269-70$.

11. Mustillo P. Binocular mechanisms mediating crossed and uncrossed stereopsis. Psychol Bull. 1985;97(2):187-201.

12. Siderov J, Harweth RS, Bedell HE. Stereopsis, cyclovergence and the backwards tilt of the vertical horopter. Vision Res. 1999;39(7):1347-57.

13. Ankrum DR. A Challenge to Eye-Level, Perpendicular-to-Gaze monitor placement. In: 13th Triennial Congress of the International Ergonomics Association. Proceedings Tampere, Finland: IEA. 1997;5:35-7.

14. Previc FH. Functional specialization in the lower and upper visual fields in humans: its ecological origins and neurophysiological implications. Behav Brain Sci. 1990;13:519-75.

15. Burian HM. Stereopsis. Doc Ophthalmol. 1951;5-6:169-83.

16. Paradiso MA, Nakayama K. Brightness perception and filling-in. Vision Res. 1991;31(7-8):1221-36.

17. Motoyoshi I. Texture filling-in and texture segregation revealed by transient masking. Vision Res. 1999;39(7):1285-91.

18. Couto MF, Brasil-Neto JP, Pessoa VF. Hemifield anisotropy for perceptual filling-in: a comparison between dichromats and trichromats [abstract]. Invest Ophthalmol Vis Sci. 2003;44(5): Abstract 1918.

19. Sakaguchi Y. Visual field anisotropy revealed by perceptual filling-in. Vision Res. 2003;43(19):2029-38.

20. Curcio CA, Allen KA. Topography of ganglion cells in human retina. J Comp Neurol. 1990;300(1):5-25.

21. Danckert J, Goodale MA. Superior performance for visually guided pointing in the lower visual field. Exp Brain Res. 2001;137(3-4):303-8.

22. Genzano VR, Di Nocera F, Ferlazzo F. Upper/lower visual field asymmetry on a spatial relocation memory task. Neuroreport. 2001;12(6):1227-30.

23. Rubin N, Nakayama K, Shapley R. Enhanced perception of illusory contours in the lower versus upper visual hemifields. Science. 1996;271(5249):651-3.

24. Bilodeau L, Faubert J. Isoluminance and chromatic motion perception throughout the visual field. Vision Res. 1997;37(15):2073-81.

25. Fukusima SS, Faubert J. Perceived length in the central visual field: evidence for visual field asymmetries. Vision Res. 2001;41(16):2119-26.

26. Lehman D, Meles HP, Mir Z. Average multichannel EEG potential fields evoked from upper and lower hemi-retina: latency differences. Eletroencephalogr Clin Neurophysiol. 1977;43(5):725-31.

27. Previc FH, Naegele PD. Target-tilt and vertical-hemifield asymmetries in freescan search for 3-D targets. Percept Psychophys. 2001;63(3):445-57.

28. Goodale MA, Milner AD. Separate visual pathways for perception and action. Trend Neurosci. 1992;15(1):20-5.

29. Sdoia S, Couyoumdjian A, Ferlazzo F. Opposite visual field asymmetries for egocentric and allocentric spatial judgments. Neuroreport. 2004;15(8):1303-5.

\section{Nos artigos enviados para publicação, o nome dos autores}

e suas afiliações devem estar completos. Isso facilitará a indexação e os links com as bases de dados e o CV Lates. 